\title{
The high covalence of metal-ligand bonds as stability limiting factor: the case of $\mathrm{Rh}(\mathrm{IX}) \mathrm{O}_{4}{ }^{+}$and $\mathrm{Rh}(\mathrm{IX}) \mathrm{NO}_{3}$
}

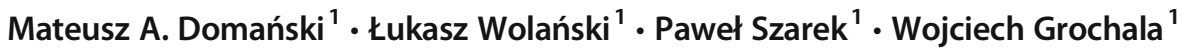

Received: 25 November 2019 / Accepted: 22 January 2020 / Published online: 7 February 2020

(C) The Author(s) 2020

\begin{abstract}
Rhodium, a 4d transition metal and a lighter analogue of iridium, is known to exhibit its highest VIth oxidation state in $\mathrm{RhF}_{6}$ molecule. In this report, the stability and decomposition pathways of two species containing rhodium at a potentially formal $+\mathrm{IX}$ oxidation state, $\left[\mathrm{RhO}_{4}\right]^{+}$and $\mathrm{RhNO}_{3}$, have been investigated theoretically within the framework of the relativistic twocomponent Hamiltonian calculations. Possible rearrangement into isomers featuring lower formal oxidation numbers has been explored. We found that both species studied are metastable with respect to elimination of $\mathrm{O}_{2}$ or $\mathrm{NO}$. However, the local minima containing $\mathrm{Rh}(\mathrm{IX})$ are protected by sufficient energy barriers on the decomposition pathway, and they could in principle be prepared. The analysis of a broader set of compounds containing group 8 and 9 metals in high formal oxidation states that correspond to the group number showed that, in contrast to a standard trend, the limits of formally attainable oxidation state correlate with high level of covalent bonding character in the complexes studied.
\end{abstract}

Keywords Oxidation states $\cdot$ Rhodium $\cdot$ Ruthenium $\cdot$ Density functional theory $\cdot$ Relativistic effects $\cdot$ Theory of chemical bonding

\section{Introduction}

The classical theory of 2-electron/2-center chemical bonding based on a molecular orbital picture, as taught to the chemistry students, puts accent on proper match of energy and "size" (i.e. spatial decay of electronic density) of atomic orbitals involved in chemical bonding. The better the match of energy and spatial distribution of orbitals (overlap), the stronger the chemical bond. Obviously, in this simplified picture, the homonuclear diatomics best fulfil the criteria which favour strong bonding, albeit heteronuclear systems may still benefit

This paper belongs to the Topical Collection Zdzislaw Latajka 70th Birthday Festschrift

This paper is dedicated to Prof. Zdzisław Latajka on his birthday.

Electronic supplementary material The online version of this article (https://doi.org/10.1007/s00894-020-4308-9) contains supplementary material, which is available to authorized users.

Łukasz Wolański

l.wolanski@cent.uw.edu.pl

Wojciech Grochala

w.grochala@cent.uw.edu.pl

1 Centre of New Technologies, University of Warsaw, Zwirki i Wigury 93, 02-089 Warsaw, Poland to a certain degree from an increased Coulombic stabilization, i.e. ionic contribution to bond energy. Take $\mathrm{C}_{2}$ molecule, with the dissociation energy of $607 \mathrm{~kJ} / \mathrm{mol}$. If one now performs "electronegativity perturbation" by substituting one $\mathrm{C}$ atom by less electronegative $\mathrm{B}$ and another $\mathrm{C}$ atom by more electronegative $\mathrm{N}$, the bonding energy is still high $(389 \mathrm{~kJ} / \mathrm{mol})$, but it markedly decreases as compared with $\mathrm{C}_{2}$. A similar trend may be noticed for many other homo- and related heteronuclear systems, with some interesting exceptions [1]. In other words, substantial covalence is often taken as an indication of strength of the chemical bonding.

The theoretical prediction and experimental observation of Ir (XI) oxidation state [2,3] have raised the questions of kinetic and thermochemical stabilities of transition metal systems with uncommonly high oxidation numbers of a metal (coinciding with the group number). The well-known group 8 complexes are represented by stable yet largely covalent $\mathrm{Os}$ (VIII) $\mathrm{O}_{4}$ and the less stable and highly reactive $\mathrm{Ru}(\mathrm{VIII}) \mathrm{O}_{4}$ while related $\mathrm{Fe}(\mathrm{VIII}) \mathrm{O}_{4}$ has never been observed but it has been predicted to be metastable [4]. Moving to the right in the periodic table, in group 9, only the observed $\left[\mathrm{IrO}_{4}\right]^{+}$cation and the recently predicted neutral molecule $\mathrm{IrNO}_{3}$ (nitride trioxide) [5] feature genuine nonavalent transition metal center. Similar to $\mathrm{Fe}$ (VIII)O $\mathrm{O}_{4}$, Ir (IX)NO $\mathrm{NO}_{3}$ has been predicted to be mildly metastable with respect to $\left(\eta^{2}-\mathrm{NO}\right) \mathrm{IrO}_{2}$ and $\left(\eta^{1}\right.$ $\mathrm{NO}) \mathrm{IrO}_{2}$ but elimination of $\mathrm{NO}$ is predicted to be protected 
by considerable barriers thus leaving some hope that Ir (IX) $\mathrm{NO}_{3}$ might be observed experimentally. The theoretical investigations of other nonavalent elements in group 9 have been rather limited. For rhodium, the highest experimentally observed oxidation state is $\mathrm{VI}_{\text {in }} \mathrm{RhF}_{6}$ [6-8]. $\mathrm{Rh}$ (IX) has only been studied in $\left[\mathrm{RhO}_{4}\right]^{+}$complex by B3LYP density functional method (DFT), with an effective core potential [2]. It has been found to be thermodynamically unstable, with exothermic energetic effect of oxygen molecule elimination estimated at $-133.2 \mathrm{~kJ} / \mathrm{mol}$ (this work does not provide any information on decomposition channels and kinetic stability). Since standard enthalpy of formation for molecular $\mathrm{RuO}_{4}$ is ca. $144 \mathrm{~kJ} / \mathrm{mol}$ smaller than for its osmium analogue [9] (which can be attributed to the smaller relativistic effects and consequently weaker destabilization of valence $\mathrm{d}$ orbitals in $\mathrm{Ru}$ as compared with Os [10]), similar decrease of the stability of the Rh(IX) complexes as compared with Ir (IX) ones might indeed be expected.

In this work, we look again at $\left[\mathrm{RhO}_{4}\right]^{+}$and for the first time at $\mathrm{RhNO}_{3}$ to determine energetics and kinetic barriers towards decomposition of both species. Comparison of these systems within a broader set of related Ru, Os and Ir high-valent species allows us to draw more general conclusions about trends of chemical bonding in the entire family.

\section{Methods}

The most of our calculations were performed using M06-L density functional which has been well validated for transition metals [11-13]. We have included the relativistic effects using two most popular ways: via Douglass-Kroll-Hess twocomponent (DKH2) Hamiltonian $[14,15]$ or utilizing zeroorder regular approximation (ZORA) [16-18]. The computations with DKH2 approach were performed with ORCA 4.0.1 program [19], and the results by ZORA were obtained in ADF 2018 [20-22]. In our calculations, we employed Gaussiantype cc-pVTZ-DK (developed in combination with DKH2) [23] and the Slater-type TZ2P (used with ZORA) [24] allelectron basis sets. The calculations performed in both used programs were done without resolution of identity and frozencore approximation.

Abovementioned calculations based on DFT were used to perform geometry optimizations of stationary point structures (minimum energy ones and transition states (TS)) and relaxed surface scans, i.e. series of constrained geometry optimizations, with stretching or shortening of selected bond distances (reaction paths). For all these structures, optimized as of electronic singlet multiplicity, single-point energies for higher multiplicities (triplet or quintet) were also obtained to find intersections that may appear on our reaction path PESs (potential energy surfaces).
In order to validate DFT predictions and to evaluate adequacy of single-determinant wave function solutions, the single-point $\operatorname{CCSD}(\mathrm{T})[25,26]$ energies with $\mathrm{DKH} 2$ Hamiltonian and cc-pVTZ-DK basis set were obtained using ORCA computational package for M06-L/DKH2 and M06-L/ ZORA equilibrium geometries (see note [27]). $T_{1}$ diagnostic parameter [28] values were analysed (see electronic supplementary material, ESI). Recent study about usefulness of this parameter among $4 \mathrm{~d}$ metal-containing molecules has statistically shown that the criterion of $T_{1}<0.045$ might be used to judge the importance of contribution of the nondynamical correlation in these systems [29].

The bond indices based on definitions by Gopinathan and Jug [30] and Nalewajski and Mrozek [31-33] (the set 2 presented by Michalak et al. [34]) has been employed. All indices were calculated using M06-L/ZORA/TZ2P method. Gopinathan-Jug index (G-J) is equivalent to the covalent two-center part of Nalewajski-Mrozek bond index (N-M), while the latter includes also two-center ionic contributions [30, 34] (for further information about the ratio of $[\mathrm{G}-\mathrm{J}] /[\mathrm{N}-\mathrm{M}]$, see ESI). Partial charges were calculated with NBO 6.0 program [35] with mentioned M06L/DKH2/cc-pVTZ-DK approach.

\section{Results and discussion}

Let us begin with two notes. Firstly, both ways of including relativistic effects used by us lead to very similar results, so we will focus here mainly on M06-L/ZORA results, while M06L/DKH2 ones are available in ESI. Secondly, the CCSD(T)/ DKH2 single-point energy calculations qualitatively agree with DFT estimates (see superposition of CCSD(T) and DFT energy values in ESI, Figs. S1, S2). Some disagreement between DFT and CCSD(T) methods appears only in the vicinity of the TS structures, where multireference character of electronic structure appears.

Analysis of the single-reference character of wave function with $T_{1}$ diagnostic parameter (Fig. 2) shows that local energy minima, such as those containing a metal at high formal oxidation state (Table 1), may be reasonably well described with single-determinant methods. This alone is an indicator that higher multiplicity states in which metal is at lower formal oxidation state do not admix substantially to the local minima of interest, particularly because they are quite distant from them in the space of internal geometry parameters of a molecule (bond lengths and angles). Calculated partial charges of $4 \mathrm{~d}$ metal atoms are about $22-24 \%$ smaller than $5 \mathrm{~d}$ metal atoms in analogous molecules $\left(22.1 \%, 22.7 \%\right.$ and $23.8 \%$ for $\mathrm{MO}_{4}$, $\left[\mathrm{MO}_{4}\right]^{+}$and $\mathrm{MNO}_{3}$ respectively, results in ESI, Table S1).

However, in the case of transition states (TSs) and their neighbourhood, single-determinant methods may be insufficient (Fig. 2). This is natural since a transition state is by 
Table 1 Calculated bond lengths and valency indices of optimized tetrahedral or quasi-tetrahedral structures of respective systems (A structures presented in Fig. 1). Experimental data for $\mathrm{OsO}_{4}$ and $\mathrm{RuO}_{4}$ are from gas phase (ED) [36, 37]; data for $\mathrm{CsOsNO}_{3}$ are from crystal structure
(XRD) [38]. Interatomic distances and bond indices come from M06-L/ ZORA computations, $T_{1}$ parameter values were calculated at $\mathrm{CCSD}(\mathrm{T}) /$ DKH2 for M06-L/DKH2 equilibrium structures

\begin{tabular}{|c|c|c|c|c|c|c|c|}
\hline \multirow[t]{2}{*}{ Molecule } & \multirow[t]{2}{*}{ Bond } & \multicolumn{2}{|c|}{ Bond length $(\AA)$} & \multicolumn{3}{|c|}{ Bond index (v.u.) } & \multirow[t]{2}{*}{$T_{1}$} \\
\hline & & Calc. & Exp. & G-J & N-M & $\frac{[\mathrm{G}-\mathrm{J}]}{[\mathrm{N}-\mathrm{M}]}(\%)$ & \\
\hline $\mathrm{OsO}_{4}$ & $\mathrm{Os}=\mathrm{O}$ & 1.706 & $1.712[36]$ & 1.43 & 1.68 & 85 & 0.016 \\
\hline $\mathrm{RuO}_{4}$ & $\mathrm{Ru}=\mathrm{O}$ & 1.691 & $1.706[37]$ & 1.37 & 1.50 & 91 & 0.022 \\
\hline$\left[\mathrm{IrO}_{4}\right]^{+}$ & $\mathrm{I} r=\mathrm{O}$ & 1.696 & - & 1.37 & 1.54 & 89 & 0.017 \\
\hline$\left[\mathrm{RhO}_{4}\right]^{+}$ & $\mathrm{Rh}=\mathrm{O}$ & 1.689 & - & 1.25 & 1.31 & 95 & 0.026 \\
\hline$\left[\mathrm{OsNO}_{3}\right]^{-}$ & $\begin{array}{l}\mathrm{Os}=\mathrm{O} \\
\mathrm{Os}=\mathrm{N}\end{array}$ & $\begin{array}{l}1.748 \\
1.685\end{array}$ & $\begin{array}{l}1.740[38] \\
1.676[38]\end{array}$ & $\begin{array}{l}1.24 \\
2.01\end{array}$ & $\begin{array}{l}1.52 \\
2.26\end{array}$ & $\begin{array}{l}82 \\
89\end{array}$ & 0.015 \\
\hline $\mathrm{IrNO}_{3}$ & $\begin{array}{l}\mathrm{Ir}=\mathrm{O} \\
\mathrm{Ir}=\mathrm{N}\end{array}$ & $\begin{array}{l}1.732 \\
1.675\end{array}$ & $\begin{array}{l}- \\
-\end{array}$ & $\begin{array}{l}1.19 \\
1.85\end{array}$ & $\begin{array}{l}1.39 \\
2.03\end{array}$ & $\begin{array}{l}86 \\
91\end{array}$ & 0.019 \\
\hline $\mathrm{RhNO}_{3}$ & $\begin{array}{l}\mathrm{Rh}=\mathrm{O} \\
\mathrm{Rh} \equiv \mathrm{N}\end{array}$ & $\begin{array}{l}1.725 \\
1.667\end{array}$ & $\begin{array}{l}- \\
-\end{array}$ & $\begin{array}{l}1.08 \\
1.69\end{array}$ & $\begin{array}{l}1.18 \\
1.73\end{array}$ & $\begin{array}{l}92 \\
98\end{array}$ & 0.039 \\
\hline
\end{tabular}

definition a multicenter-bonded hybrid of the substrates and products of the chemical reaction, and a minimum set of two Slater determinants is needed to describe it. Some hope gives us the fact that DFT is less sensitive to the multireference character than wave function-based computations, especially when functionals with small amount of HF exchange are used (such as M06-L one, with 0\% HF contribution, applied in this work). Thus, being aware of approximate character of our investigations, sometimes it is a good idea to focus on DFT values rather than $\operatorname{CCSD}(\mathrm{T})$ ones. Based on DFT data, we found out that for some TSs, the triplet energies at the geometry of singlet solutions are lower than those of the parent singlets. This obviously reduces the effective energetic barriers on the reaction pathway leading to ${ }^{3} \mathrm{O}_{2}$ or ${ }^{2} \mathrm{NO}$ elimination and associated with lowering of central metal ion formal oxidation number (Fig. 1). This means that the energy barriers computed in this work should be treated with the grain of salt, and they are likely smaller than the values discussed.

As expected, $\mathrm{RuO}_{4}$ was found to be stable with respect to $\left(\eta^{2}-\mathrm{O}_{2}\right) \mathrm{MO}_{2}$ (minimum marked as $\mathrm{C}_{\mathrm{OO}}$ in Fig. 1) and $\left(\eta^{1}-\right.$ $\left.\mathrm{O}_{2}\right) \mathrm{MO}_{2}$ states (minimum $\mathrm{E}_{\mathrm{OO}}$ ), while rendering the isomerization an "energy uphill" process by $141.5 \mathrm{~kJ} / \mathrm{mol}$ and $281.0 \mathrm{~kJ} / \mathrm{mol}$, respectively. The first of those, which governs energetic stability of the tetrahedral minimum, is, however, smaller than that for $\mathrm{OsO}_{4}$ of $428 \mathrm{~kJ} / \mathrm{mol}$ with M06-L/ ZORA approach [5] (cf. $380.7 \mathrm{~kJ} / \mathrm{mol}$ at B3LYP/ECP level [39]). The transition state $\left(\mathrm{B}_{\mathrm{OO}}\right)$ on the pathway of $\mathrm{O}_{2}$ elimination from ruthenium tetraoxide resembles the transition state in the case of osmium tetraoxide [5, 39], and it corresponds to $\mathrm{O}-\mathrm{O}$ bond formation during isomerization process: $\mathrm{MO}_{4} \leftrightarrow\left(\eta^{2}-\mathrm{O}_{2}\right) \mathrm{MO}_{2}$. Recall that the high kinetic stability of tetraoxide complexes with metal on +8 oxidation state is secured in $\mathrm{OsO}_{4}$ with the huge barrier of $406.3 \mathrm{~kJ} / \mathrm{mol}$ on singlet PES and the corresponding barrier on the triplet PES of
$334.4 \mathrm{~kJ} / \mathrm{mol}$ [5] (cf. $394.3 \mathrm{~kJ} / \mathrm{mol}$ in [39]). The height of isomerisation barrier (on the pathway from $\mathrm{A}$ to $\mathrm{B}_{\mathrm{OO}}$ ) for tetrahedral $\mathrm{RuO}_{4}$ is again smaller but still substantial, i.e. $318.7 \mathrm{~kJ} / \mathrm{mol}$ and $225.1 \mathrm{~kJ} / \mathrm{mol}$ on singlet/triplet PES (see Fig. 1a, and Fig. S3a for comparison with M06-L/ DKH2 approach).

Having discussed the results for important reference compounds containing group 8 metals, let us now move to group 9 , which is our main focus here. Wang et al. found out that isomerization from tetrahedral $\left[\mathrm{IrO}_{4}\right]^{+}$to $\left[\left(\eta^{2}-\mathrm{O}_{2}\right) \mathrm{IrO}_{2}\right]^{+}$is an endoergic process by $40 \mathrm{~kJ} / \mathrm{mol}$ (B3LYP/ZORA with spinorbit coupling) or $89 \mathrm{~kJ} / \mathrm{mol}(\mathrm{CCSD}(\mathrm{T}) / \mathrm{ECP})$ [3]. The respective barrier of first reaction step has been estimated to $190 \mathrm{~kJ} /$ mol [3]. This compares nicely with the values of $91 \mathrm{~kJ} / \mathrm{mol}$ for isomerization and $198 \mathrm{~kJ} / \mathrm{mol}$ for energy barrier which we have obtained using M06-L/ZORA method and SARCZORA basis set [40] (Fig. S4). In contrast to $\left[\mathrm{IrO}_{4}\right]^{+}$, we found (Fig. 1b) that $\left[\mathrm{RhO}_{4}\right]^{+}$is metastable with respect to $\left(\eta^{2}-\right.$ $\left.\mathrm{O}_{2}\right) \mathrm{RhO}_{2}$ isomer, which is by $71.2 \mathrm{~kJ} / \mathrm{mol}$ lower in energy.

However, the kinetic stability of $\left[\mathrm{RhO}_{4}\right]^{+}$is secured with the large barrier of $240.2 \mathrm{~kJ} / \mathrm{mol}$ at singlet PES and still appreciable one of $\sim 87 \mathrm{~kJ} / \mathrm{mol}$ at triplet PES (as estimated at singlet-triplet PES crossing, see Fig. S5b). Therefore this case is similar to $\mathrm{FeO}_{4}$ specie (with iron in +VIII formal oxidation state), which is metastable with respect to $\left(\eta^{2-} \mathrm{O}_{2}\right) \mathrm{Fe}^{\mathrm{VI}} \mathrm{O}_{2}$ by $-44 \mathrm{~kJ} / \mathrm{mol}$ and yet kinetically protected by a barrier of $174 \mathrm{~kJ} / \mathrm{mol}$ at CCSD(T)/ECP level [4]. In the same study at DFT (PBE)/ECP method, these two minima are nearly degenerated in terms of energy $(0.1 \mathrm{~kJ} / \mathrm{mol})$ and a barrier between them equals $121 \mathrm{~kJ} / \mathrm{mol}$ [4].

The reaction path leading to partial $\mathrm{O}_{2}$ elimination from the neutral quasi-tetrahedral $\mathrm{IrNO}_{3}$ molecule has been recently determined to be endoergic by $200.4 \mathrm{~kJ} / \mathrm{mol}$, and the $\mathrm{NO}$ elimination pathway exoergic by $-89 \mathrm{~kJ} / \mathrm{mol}$, but the 
a

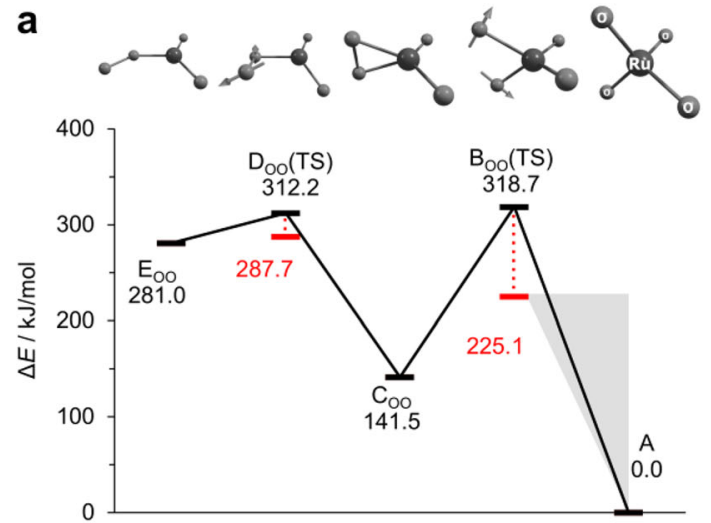

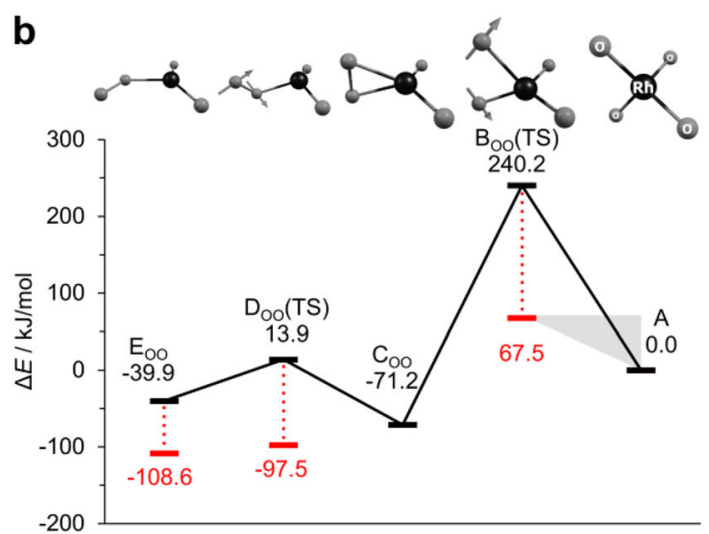

C

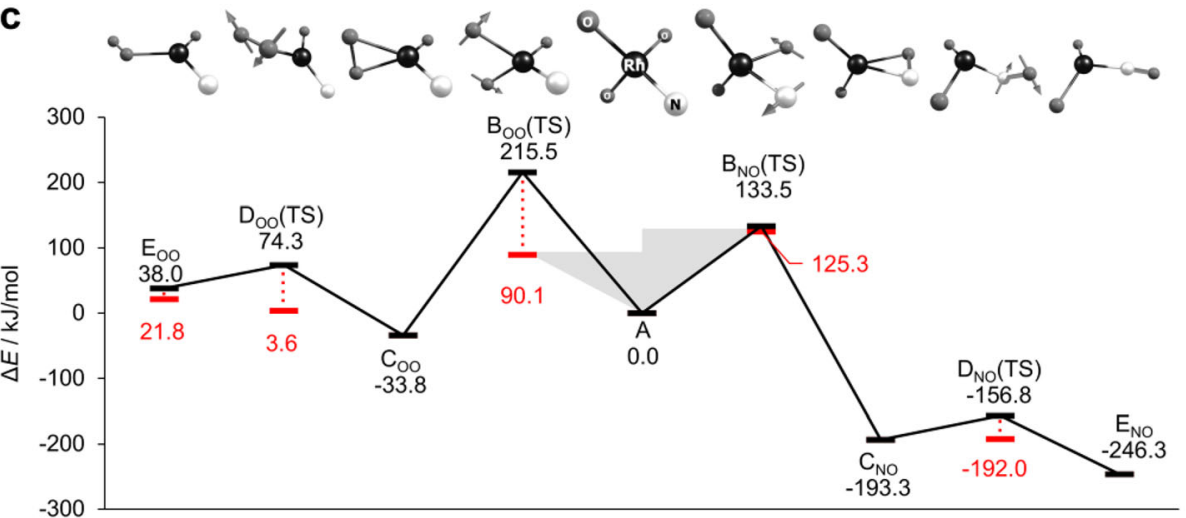

Fig. 1 Relative energies calculated at M06-L/ZORA level of theory for minimum-energy structures and transition states of singlet multiplicities for $\mathrm{RuO}_{4}(\mathbf{a}),\left[\mathrm{RhO}_{4}\right]^{+}$(b) and $\mathrm{RhNO}_{3}(\mathbf{c})$ systems. Single-point energies of all structures in their electronic triplet configurations (red bars and dashed lines) exhibiting energies lower than singlets are shown. Grey area highlights energetic barriers around minimum A. Relevant equilibrium structures are visualized above each graph. Two largest displacement vectors of imaginary frequency are presented for each transition state. Energy of minimum A corresponding to the largest formal valence of transition metal has been set to zero minimum of interest was found to be surrounded by two comparable energy barriers of about $208 \mathrm{~kJ} / \mathrm{mol}$ [5]. In the case of its rhodium analogue, $\mathrm{RhNO}_{3}$, the $\left(\eta^{2}-\mathrm{O}_{2}\right) \mathrm{RhNO}$ state is lower by $-33.8 \mathrm{~kJ} / \mathrm{mol}$ from the quasi-tetrahedral $\mathrm{Rh}(\mathrm{IX}) \mathrm{NO}_{3}$, and the associated singlet-triplet crossing which creates a barrier is about 35\% smaller than for the Ir complex but still quite large $\left(\sim 154 \mathrm{~kJ} / \mathrm{mol}\right.$, Fig. S5). On the other hand, $\left(\eta^{1}-\mathrm{O}_{2}\right)$ $\mathrm{RhNO}$ triplet at the geometry of a corresponding singlet is higher in energy than the tetrahedral minimum A (Fig. 1c) by $21.8 \mathrm{~kJ} / \mathrm{mol}$. Although in $\mathrm{RhNO}_{3}$, the $\mathrm{NO}$ reaction path is as exoergic as by $-246.3 \mathrm{~kJ} / \mathrm{mol}$, the $\left(\eta^{2}-\mathrm{NO}\right) \mathrm{RhO}_{2}$ state $\left(\mathrm{C}_{\mathrm{NO}}\right)$ is much more energetically stable $(-193.3 \mathrm{~kJ} / \mathrm{mol})$ than $\mathrm{RhNO}_{3}$ isomer with central atom formally in +9 oxidation state (Fig. 1c). The key energy barrier on the $\mathrm{NO}$ elimination pathway which governs kinetic stability of $\mathrm{RhNO}_{3}$ is large $(125.3 \mathrm{~kJ} / \mathrm{mol})$ and comparable with that for the $\mathrm{O}_{2}$ elimination. Concluding this paragraph, one should state that both $\left[\mathrm{RhO}_{4}\right]^{+}$and $\mathrm{RhNO}_{3}$ seem to be sufficiently kinetically stable to be observed in experiment at low temperature.

In the case of both rhodium (+IX) complexes, the $T_{1}$ diagnostic increases (up to 0.06 , see Fig. 2) while distance between $\mathrm{O} \cdots \mathrm{O}$ and $\mathrm{N} \cdots \mathrm{O}$ ligand decrease, thus indicating a growing multireference character of the wave function even before the DFT-calculated singlet transition states are reached. That agrees well with obtained singlet-triplet crossings on PES scans Fig. S5. Again, this means that the actual barriers will be smaller than those presented in Fig. 2.

Supplementary information to energetical considerations is provided by systematic coincidence between degree of ionic/covalent character of metal-ligand bonds and energy lowering upon isomerization from high oxidation number state into the next local minimum. The concept of percentage covalent or ionic character of a bond is associated with bond polarization and charge transfer effects and from orbital viewpoint might be attached to probability of simultaneously finding two electrons on atoms A and B. It turns out that nice interpretation is provided based on covalent and ionic valence indices [41]. The covalent valence index, a measure of atom polarization and the amount of charge transfer, might be defined relative to changes in the electron "pairings" in molecule with respect to separated atom/ion limit [41]. The degree of covalence is evaluated through a ratio of bond multiplicity indices [42]:

$\%$ of covalent character $=\frac{b_{\mathrm{G}-\mathrm{J}}}{b_{\mathrm{N}-\mathrm{M}}}$ 
a

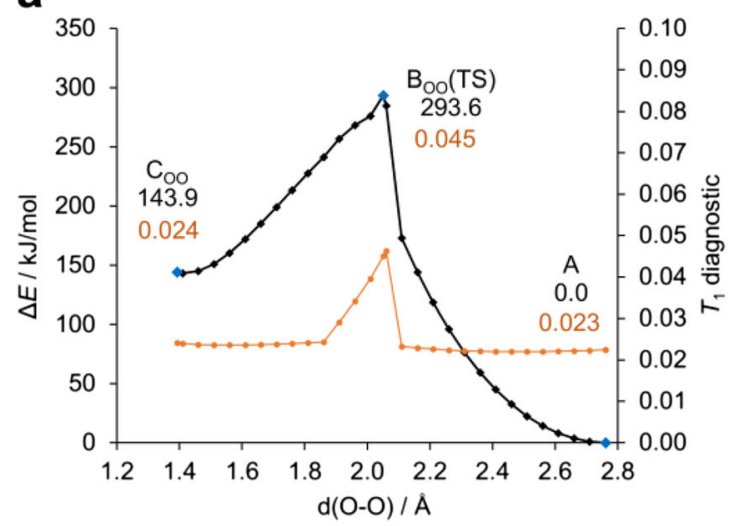

b

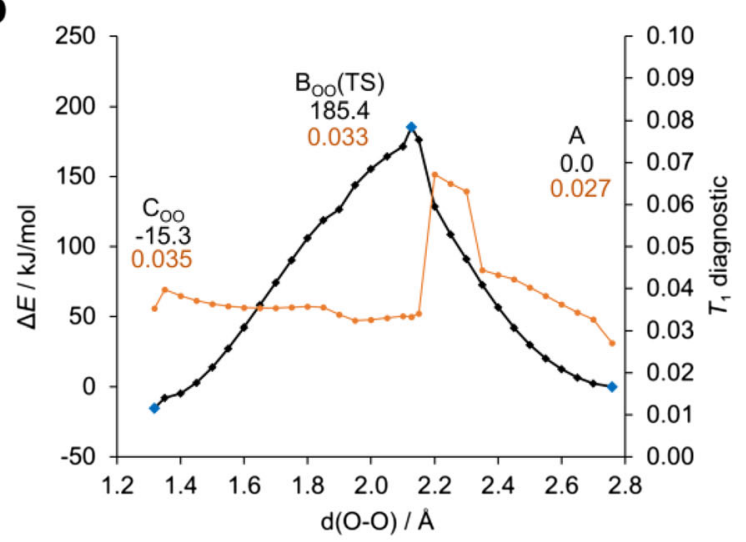

C

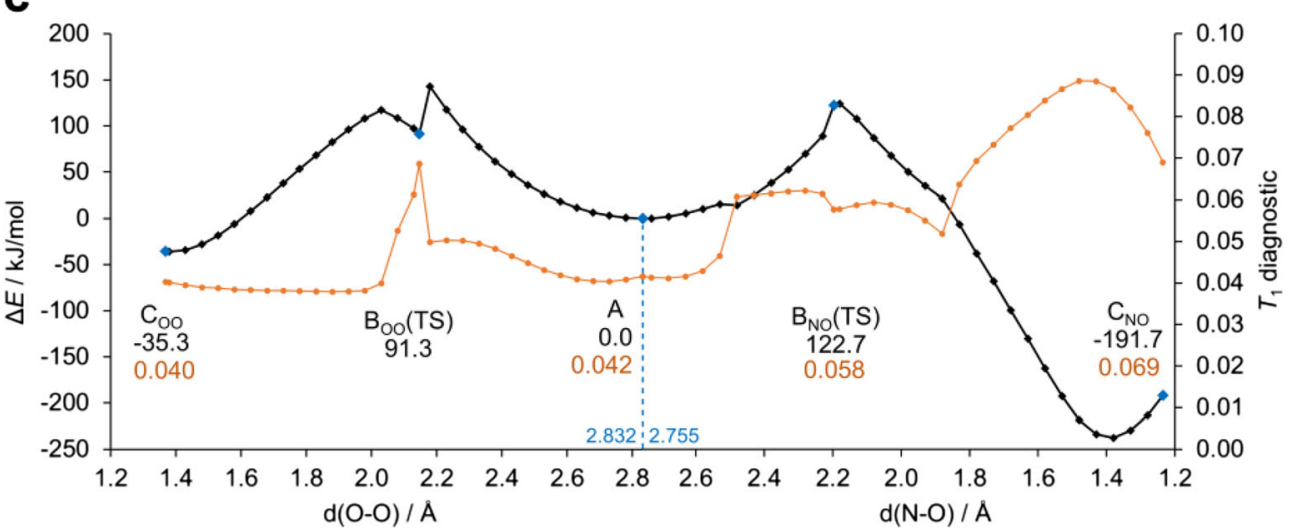

Fig. $2 \mathrm{CCSD}(\mathrm{T}) / \mathrm{DKH} 2$ relative energy profiles of reactions of dissociations of $\mathrm{NO}$ and $\mathrm{O}_{2}$ ligands from $\mathrm{RuO}_{4}(\mathbf{a}),\left[\mathrm{RhO}_{4}\right]^{+}(\mathbf{b})$ and $\mathrm{RhNO}_{3}$ (c) systems. Equilibrium geometries constituting reaction paths were obtained with M06-L/ZORA method (from Fig. S5). Interatomic distances $\mathrm{d}(\mathrm{O}-\mathrm{O})$ and $\mathrm{d}(\mathrm{N}-\mathrm{O})$ stand for the internal reaction coordinates, i.e. $\mathrm{O} \cdots \mathrm{O}$ and $\mathrm{N} \cdots \mathrm{O}$ separation, respectively. The $T_{1}$ diagnostic parameter

It is essential that the ionic and covalent valence numbers, used to determine $b_{\mathrm{G}-\mathrm{J}}$ and $b_{\mathrm{N}-\mathrm{M}}$, are defined within the same theoretical framework offering a consistent set. Moreover, diatomic contributions in this method are independent of the atomic reference, as well as not much sensitive to basis set, hence reliable [34, 41]. The G-J index is based on sum of squares of density matrix elements corresponding to pairs of orbitals cantered on different atoms, which is conceptually close to classical Lewis representation of covalent interaction as shared electron pairs. The covalent indices are related to exchange part of the twoparticle density matrix. The N-M index includes the former covalent as well as the ionic contributions (originating from the Coulomb part of the two-particle density matrix), both affecting the fractional bond character.

The analysis of the ratio of G-J to N-M indices in our systems (Fig. 3) shows that the $\mathrm{M}=\mathrm{O}$ bonds in tetraoxospecies of Os and Ir have considerable covalent character (85-89\%). The analogous species of lighter $4 \mathrm{~d}$ elements, $\mathrm{Ru}$ and $\mathrm{Rh}$, respectively, exhibit even more covalent bonding $(91-95 \%)$. On the other hand, the $\mathrm{Ir}=\mathrm{O}$ bonds in $\mathrm{IrNO}_{3}$ show values are also placed on the plots. In the case of $\mathrm{d}(\mathrm{O}-\mathrm{O}) \mathrm{RhNO}_{3}$, increase of multireference character around Boo probably causes abrupt energy dependence. Blue points indicate energies of the stationary point structures from DFT calculations. We found comparable results with M06-L/DKH2 (Figs. S6, S7 in ESI). Energy of minimum A has been set to zero

similar covalence as $\mathrm{Os}=\mathrm{O}$ ones in $\mathrm{OsO}_{4}(86-89 \%)$ while the $\mathrm{Ir}=\mathrm{N}$ bond is more covalent $(91 \%)$. Again, and as expected,

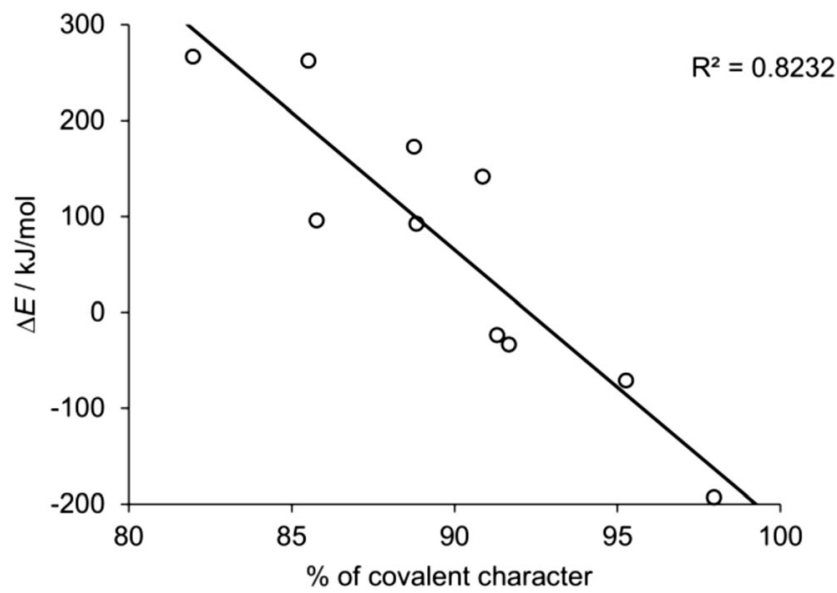

Fig. 3 The energy of $\left(\eta^{2}-\mathrm{O}_{2}\right) \mathrm{MO}_{2} /\left(\eta^{2}-\mathrm{O}_{2}\right) \mathrm{MNO}$ or $\left(\eta^{2}-\mathrm{NO}\right) \mathrm{MO}_{2}$ states with respect to $\mathrm{MO}_{4} / \mathrm{MNO}_{3}$ in relation to level of covalent bonding in $\mathrm{M}=\mathrm{O}$ or $\mathrm{M} \equiv \mathrm{N}$ determined as the ratio of $\mathrm{G}-\mathrm{J}$ to $\mathrm{M}-\mathrm{N}$ bond indices for $\mathrm{Ru}$, $\mathrm{Os}, \mathrm{Rh}$ and Ir tetraoxide and nitride trioxide complexes. Energies and bond indices calculated at M06-L/ZORA level of theory 
moving to the $4 \mathrm{~d}$ element in this series increases covalence with respect to its $5 \mathrm{~d}$ counterpart. Thus, the $\mathrm{Rh}=\mathrm{O}$ bond covalence in $\mathrm{RhNO}_{3}(92 \%)$ corresponds to that of the $\mathrm{Ru}=\mathrm{O}$ in $\mathrm{RuO}_{4}$ while the $\mathrm{Rh} \equiv \mathrm{N}$ bond shows the highest value of all studied here (98\%).

The increased covalent character of bonding in the complex causes the decrease of the effective central atom charge thus contributes to the ease of isomerization to the form having formally a lower oxidation number. Indeed, there appears to be general correlation between level of covalent bonding character in $\mathrm{M}=\mathrm{O}$ or $\mathrm{M} \equiv \mathrm{N}$ bonds of tetroxide or nitride trioxide complexes and energetic stability of $\mathrm{MO}_{4}$ or $\mathrm{MNO}_{3}$ with respect to $\left(\eta^{2}-\mathrm{O}_{2}\right) \mathrm{MO}_{2} /\left(\eta^{2}-\right.$ $\left.\mathrm{O}_{2}\right) \mathrm{MNO}$ or $\left(\eta^{2}-\mathrm{NO}\right) \mathrm{MO}_{2}$ states (Fig. 3).

\section{Conclusions}

The geometry, energetics and energy barriers protecting local minima have been computed here for $\mathrm{RuO}_{4},\left[\mathrm{RhO}_{4}\right]^{+}$and $\mathrm{RhNO}_{3}$ using DFT calculations and cross-checked using the $\operatorname{CCSD}(\mathrm{T})$ method with relativistic two-component Hamiltonians. A tetrahedral rhodium tetraoxide cation seems to be truly single-reference metastable minimum on PES though its isomerisation leading to the decrease of the formal oxidation state of a metal has no significant energetic barriers. The quasi-tetrahedral $\mathrm{RhNO}_{3}$ species seems to exhibit larger barriers against isomerisation (>120 kJ/mol) but it has a stronger multireference character itself. The energetic and kinetic stability of mentioned molecules containing $\mathrm{Rh}$ (IX) is comparable with those of $\mathrm{Fe}(\mathrm{VIII}) \mathrm{O}_{4}$ [4]. Because the $T_{1}$ parameter for $\mathrm{Rh}$ system scans is close or exceeds at some points, the limiting value, especially for the NO elimination reaction pathway, the multireference methods [4] should be applied in the future to gain a deeper insight into decomposition pathways and barriers. Nevertheless, our preliminary results suggest that existence of small molecules with $\mathrm{Rh}$ in +IX oxidation state is conceivable, especially at very low temperatures.

We also found that high covalence of chemical bonding, as measured by the ratio of G-J to N-M indices (ESI), is associated with high susceptibility of a molecule to reconfigure into an isomer showing lower oxidation state of a transition metal. While this seems to be expected for heteroatomic molecules (an inverse ligand field implies a redox reaction [43]), yet it remains in stark contrast to what is usually observed for homonuclear systems.

Acknowledgements Calculations were performed at the Wroclaw Centre for Networking and Supercomputing. WG acknowledges statutory BST funds.

Funding information This research was supported by the Polish National Science Centre NCN under the OPUS grant Hi-Ox (2016/21/B/ST4/ 03866).
Open Access This article is licensed under a Creative Commons Attribution 4.0 International License, which permits use, sharing, adaptation, distribution and reproduction in any medium or format, as long as you give appropriate credit to the original author(s) and the source, provide a link to the Creative Commons licence, and indicate if changes were made. The images or other third party material in this article are included in the article's Creative Commons licence, unless indicated otherwise in a credit line to the material. If material is not included in the article's Creative Commons licence and your intended use is not permitted by statutory regulation or exceeds the permitted use, you will need to obtain permission directly from the copyright holder. To view a copy of this licence, visit http://creativecommons.org/licenses/by/4.0/.

\section{References}

1. Cottrell TL (1958) The strengths of chemical bonds. Academic Press

2. Himmel D, Knapp C, Patzschke M, Riedel S (2010) How far can we go? Quantum-chemical investigations of oxidation state $+\mathrm{IX}$. ChemPhysChem 11:865-869. https://doi.org/10.1002/cphc. 200900910

3. Wang G, Zhou M, Goettel JT et al (2014) Identification of an iridium-containing compound with a formal oxidation state of IX. Nature 514:475-477. https://doi.org/10.1038/nature13795

4. Huang W, Xing D-H, Lu J-B et al (2016) How much can density functional approximations (DFA) fail? The extreme case of the FeO4 species. J Chem Theory Comput 12:1525-1533. https://doi. org/10.1021/acs.jctc.5b01040

5. Wolanski L, Domanski M, Szarek P, Grochala W (2019) Beyond oxides: nitride as a ligand in a neutral IrIXNO3 molecule bearing transition metal at high oxidation state. Chem Eur J. https://doi.org/ 10.1002/chem.201902142

6. Chernick CL, Claassen HH, Weinstock B (1961) Rhodium HEXAFLUORIDE1. J Am Chem Soc 83:3165-3166. https://doi. org/10.1021/ja01475a046

7. Craciun R, Long RT, Dixon DA, Christe KO (2010) Electron affinities, fluoride affinities, and heats of formation of the second row transition metal hexafluorides: MF6 ( $\mathrm{M}=\mathrm{Mo}, \mathrm{Tc}, \mathrm{Ru}, \mathrm{Rh}, \mathrm{Pd}, \mathrm{Ag})$. J Phys Chem A 114:7571-7582. https://doi.org/10.1021/jp1022949

8. Craciun R, Picone D, Long RT et al (2010) Third row transition metal hexafluorides, extraordinary oxidizers, and Lewis acids: electron affinities, fluoride affinities, and heats of formation of WF6, ReF6, OsF6, IrF6, PtF6, and AuF6. Inorg Chem 49:1056-1070. https://doi.org/10.1021/ic901967h

9. Düllmann CE, Eichler B, Eichler R et al (2002) On the stability and volatility of group 8 tetroxides, $\mathrm{MO} 4(\mathrm{M}=$ ruthenium, osmium, and hassium $(Z=108))$. J Phys Chem B 106:6679-6684. https://doi. org/10.1021/jp0257146

10. Heß BA (1997) Relativistic effects in heavy-element chemistry. Ber Bunsenges Phys Chem 101:1-10. https://doi.org/10.1002/bbpc. 19971010102

11. Zhao Y, Truhlar DG (2006) A new local density functional for main-group thermochemistry, transition metal bonding, thermochemical kinetics, and noncovalent interactions. J Chem Phys 125:194101. https://doi.org/10.1063/1.2370993

12. Peverati R, Truhlar DG (2014) Quest for a universal density functional: the accuracy of density functionals across a broad spectrum of databases in chemistry and physics. Philos Trans R Soc A Math Phys Eng Sci 372:20120476. https://doi.org/10.1098/rsta.2012.0476

13. Hao P, Sun J, Xiao B et al (2013) Performance of meta-GGA functionals on general main group thermochemistry, kinetics, and noncovalent interactions. J Chem Theory Comput 9:355-363. https://doi.org/10.1021/ct300868x 
14. Douglas M, Kroll NM (1974) Quantum electrodynamical corrections to the fine structure of helium. Ann Phys 82:89-155. https:// doi.org/10.1016/0003-4916(74)90333-9

15. Hess BA (1986) Relativistic electronic-structure calculations employing a two-component no-pair formalism with externalfield projection operators. Phys Rev A 33:3742-3748. https://doi. org/10.1103/PhysRevA.33.3742

16. van Lenthe E, Baerends EJ, Snijders JG (1996) Construction of the Foldy-Wouthuysen transformation and solution of the Dirac equation using large components only. J Chem Phys 105:2373-2377. https://doi.org/10.1063/1.472104

17. van Lenthe E, Snijders JG, Baerends EJ (1996) The zero-order regular approximation for relativistic effects: the effect of spinorbit coupling in closed shell molecules. J Chem Phys 105:65056516. https://doi.org/10.1063/1.472460

18. Wüllen CV (1999) Relativistic all-electron density functional calculations. J Comput Chem 20:51-62. https://doi.org/10.1002/ (SICI)1096-987X(19990115)20:1<51::AID-JCC7>3.0.CO;2-K

19. Neese F (2012) The ORCA program system. Wiley Interdiscip Rev Comput Mol Sci 2:73-78. https://doi.org/10.1002/wcms.81

20. Fonseca Guerra C, Snijders JG, te Velde G, Baerends EJ (1998) Towards an order-N DFT method. Theor Chem Accounts 99:391403. https://doi.org/10.1007/s002140050353

21. te Velde G, Bickelhaupt FM, Baerends EJ et al (2001) Chemistry with ADF. J Comput Chem 22:931-967. https://doi.org/10.1002/ jcc. 1056

22. Baerends EJ, Ziegler T, Atkins AJ et al ADF2018, SCM, Theoretical chemistry. Vrije Universiteit, Amsterdam https:// www.scm.com

23. Peterson KA, Figgen D, Dolg M, Stoll H (2007) Energy-consistent relativistic pseudopotentials and correlation consistent basis sets for the 4d elements Y-Pd. J Chem Phys 126:124101. https://doi.org/ $10.1063 / 1.2647019$

24. Lenthe EV, Baerends EJ (2003) Optimized Slater-type basis sets for the elements 1-118. J Comput Chem 24:1142-1156. https://doi. org/10.1002/jcc. 10255

25. Paldus J, Čížek J, Shavitt I (1972) Correlation problems in atomic and molecular systems. IV. Extended coupled-pair many-electron theory and its application to the $\mathrm{B} \$\{\text { mathrm }\{\mathrm{H}\}\}_{-}\{3\} \$$ molecule. Phys Rev A 5:50-67. https://doi.org/10.1103/PhysRevA.5.50

26. Watts JD, Gauss J, Bartlett RJ (1993) Coupled-cluster methods with noniterative triple excitations for restricted open-shell Hartree-Fock and other general single determinant reference functions. Energies and analytical gradients. J Chem Phys 98:8718-8733. https://doi. org/10.1063/1.464480

27. Unfortunately, we were not able to calculate $\operatorname{CCSD}(\mathrm{T})$ energy with ZORA Hamiltonian for geometries obtained with M06-L/ZORA approach due to lack of Gaussian-type basis set for $4 \mathrm{~d}$ elements suitable to use with ZORA

28. Lee TJ, Taylor PR (1989) A diagnostic for determining the quality of single-reference electron correlation methods. Int J Quantum Chem 36:199-207. https://doi.org/10.1002/qua.560360824
29. Wang J, Manivasagam S, Wilson AK (2015) Multireference character for $4 \mathrm{~d}$ transition metal-containing molecules. J Chem Theory Comput 11:5865-5872. https://doi.org/10.1021/acs.jctc.5b00861

30. Gopinathan MS, Jug K (1983) Valency. I. A quantum chemical definition and properties. Theor Chim Acta 63:497-509. https:// doi.org/10.1007/BF02394809

31. Nalewajski RF, Mrozek J, Mazur G (1996) Quantum chemical valence indices from the one-determinantal difference approach. Can J Chem 74:1121-1130. https://doi.org/10.1139/v96-126

32. Nalewajski RF, Mrozek J, Michalak A (1997) Two-electron valence indices from the Kohn-Sham orbitals. Int J Quantum Chem 61:589 601. https://doi.org/10.1002/(SICI)1097-461X(1997)61:3<589:: AID-QUA28>3.0.CO;2-2

33. Mrozek J, Nalewajski RF, Michalak A (1998) Exploring bonding patterns of molecular systems using quantum mechanical bond multiplicities. Pol J Chem:1779-1791

34. Michalak A, DeKock RL, Ziegler T (2008) Bond multiplicity in transition-metal complexes: applications of two-electron valence indices. J Phys Chem A 112:7256-7263. https://doi.org/10.1021/ jp800139g

35. Glendening ED, Landis CR, Weinhold F (2013) NBO 6.0: natural bond orbital analysis program. J Comput Chem 34:1429-1437. https://doi.org/10.1002/jcc. 23266

36. Seip HM, Stolevik R (1966) Studies on the failure of the first born approximation in electron diffraction. Acta Chim Scand 20:385-394

37. Schafer L, Seip HM (1967) Studies on failure of first born approximation in electron diffraction. 6. Ruthenium tetraoxide. Acta Chim Scand 21:737

38. Pastuszak R, L'Haridon P, Marchand R, Laurent Y (1982) Structure du nitrurotrioxoosmate (VIII) de césium, $\mathrm{CsOsO} 3 \mathrm{~N}$; comparaison avec BaSO4. Acta Crystallogr B 38:1427-1430. https://doi.org/10. 1107/S0567740882006086

39. Gong Y, Zhou M, Kaupp M, Riedel S (2009) Formation and characterization of the iridium tetroxide molecule with iridium in the oxidation state +VIII. Angew Chem Int Ed Eng 48:7879-7883. https://doi.org/10.1002/anie.200902733

40. Pantazis DA, Chen X-Y, Landis CR, Neese F (2008) All-electron scalar relativistic basis sets for third-row transition metal atoms. J Chem Theory Comput 4:908-919. https://doi.org/10.1021/ ct800047t

41. Nalewajski RF, Köster AM, Jug K (1993) Chemical valence from the two-particle density matrix. Theor Chim Acta 85:463-484. https://doi.org/10.1007/BF01112985

42. Szarek P, manuscript in preparation (2020)

43. Hoffmann R, Alvarez S, Mealli C et al (2016) From widely accepted concepts in coordination chemistry to inverted ligand fields. Chem Rev 116:8173-8192. https://doi.org/10.1021/acs.chemrev. $6 \mathrm{~b} 00251$

Publisher's note Springer Nature remains neutral with regard to jurisdictional claims in published maps and institutional affiliations. 